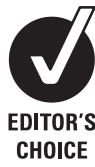

CHOICE

\title{
Injuries among male and female World Cup alpine skiers
}

\author{
T W Flørenes, T Bere, L Nordsletten, S Heir, R Bahr
}

Oslo Sports Trauma Research Center, Department of Sports Medicine, Norwegian School of Sport Sciences, Oslo, Norway

Correspondence to:

Dr T W Flørenes, Oslo Sports Trauma Research Center, Norwegian School of Sport Sciences, PB 4014 Ullevål Stadion, N-0806 Oslo, Norway; tonje.wale.florenes@nih.no

Accepted 13 October 2009

\section{ABSTRACT}

Background: Limited knowledge exists on injuries among professional alpine skiers.

Objective: To describe the risk of injury and the injury pattern among competitive World Cup alpine skiers during the competitive season.

Methods: Retrospective interviews were performed with all World Cup athletes from 10 nations at the end of the 2006-7 and 2007-8 winter seasons, and all acute injuries occurring during the 4.5-month competitive season were recorded. If the athlete was not present, their coaches or medical personnel were interviewed.

Results: A total of 191 acute injuries were recorded among 521 World Cup alpine skiers. As many as 86 injuries (45\%) occurred during World Cup/World Ski Championship competitions, corresponding to an injury rate of 9.8 injuries per 1000 runs $(95 \% \mathrm{Cl} 7.8$ to 11.9$)$. The injury rate was found to increase with increasing speed (slalom 4.9 injuries per 1000 runs, 95\% Cl 2.5 to 7.4-giant slalom 9.2, 5.1 to 13.3-super-G 11.0, 5.2 to 16.8-downhill 17.2, 11.6 to 22.7). The most frequently injured body part was the knee, with 68 injuries (36\%), and 37 of these were severe. The overall injury rate was higher in males than in females, but not for knee injuries. Conclusions : The risk of injury among World Cup athletes in alpine skiing is even higher than previously reported. The knee is the most commonly injured body part and with many severe injuries. Injury rate increased with a higher speed and was higher among males than in females.

Alpine skiing has been on the Olympic programme since 1936. The first World Cup ski race was held in 1967, and today the World Cup alpine skiing events include downhill, super-G (super giant slalom), giant slalom and slalom. The International Ski Federation (FIS) arranged 3087 and 3625 alpine races internationally during the 2006-7 and 2007-8 season, respectively. The number of races for the alpine skiing World Cup was 71 and 74 for the same two seasons and 453 and 443 athletes competed in these competitions. The alpine World Cup is popular, and TV audiences of up to 250 million watch an event (FIS, personal communication, 2009).

While the injury risk for recreational skiers has been well documented based on prospective injury recording systems since the early $1970 \mathrm{~s},{ }^{1-3}$ there are almost no data published on the injury pattern and injury risk for competitive alpine skiers. Recent data on professional skiers competing in diverse disciplines from downhill with high speed, long jumps and minimal protection to slalom with technical demands are limited to two single-event studies (Olympic Games 1994 and Junior World
Championships 1995). ${ }^{45}$ However, several crosssectional studies among active skiers have shown that $72-83 \%$ of world class skiers have sustained at least one previous serious injury. ${ }^{6-9}$ Although these studies are decades old, they indicate that the risk of injuries is high.

The aim of this study was therefore to describe the risk of injury and the injury pattern among competitive World Cup alpine skiers during the competitive season.

\section{METHODS}

\section{Study design and population}

We conducted retrospective interviews with World Cup alpine skiers from 10 nations at the end of the 2006-7 and the 2007-8 winter seasons because a methodological study ${ }^{10}$ found this to be the best method available to record injuries among World Cup ski and snowboard athletes. We defined the winter season as starting on 1 November or, if earlier, the first World Cup race of the season, lasting until the interviews took place. For the 2006-7 season, the first World Cup alpine event was in Levi, Finland on 11-12 November. The first races scheduled in Sölden, Austria 28-29 October were cancelled because of a lack of snow. Therefore, the injury registration started on 1 November in this season, and we conducted the interviews at the two final World Cup events in Kvitfjell, Norway (8-10 March 2007) and Lenzerheide, Switzerland (14-18 March 2007). For the 2007-8 season, the first World Cup alpine event was in Sölden, Austria on 27-28 October, and the registration for this season started there. We conducted the interviews at the two final World Cup events in Kvitfjell, Norway (27 February to 2 March 2008) and Bormio, Italy (10-16 March 2008).

From the official FIS database, we identified athletes who had started in at least one World Cup (WC)/World Ski Championship (WSC) event in downhill, super-G, giant slalom, slalom, combined or super combined. We included all athletes from the teams of Germany, Switzerland, Canada, Finland, France, Norway, Italy, Sweden, Austria and Slovenia (2007-8 only). These represent large teams in the different disciplines, and we expected most of their athletes to speak English fluently.

At the events, we interviewed the athletes from the selected nations who were present in person. If the athlete was not present (due to injury or for other reasons), we interviewed their coaches. Some coaches directed us to their team physician/ physical therapist to obtain the information needed. We also asked the team coaches to control and complete the list of athletes from their nation. 
Athletes not defined as being on the World Cup team roster by the coaches were excluded (eg, national athletes starting in races in that country on the national quota).

We explained the purpose and procedure of the interviews at the team captain's meeting, where head coaches from all nations were required to be present. At this meeting, we also asked the coaches to inform their athletes of the interviews. A letter describing the interviews was distributed by email to all head coaches/team leaders in the alpine World Cup prior to the 2007-8 registration. Research teams from the Oslo Sports Trauma Research Center consisting of physicians and physical therapists conducted the interviews. The research teams performed the interviews in the finishing area in connection with official training or competition, or, in some cases, at the team's hotel. To facilitate athlete recall of participation and time loss due to injury, we used a form outlined as the week-byweek calendar of the alpine World Cup season as an interview tool. ${ }^{10}$

The Regional Committee for Medical Research Ethics, Region Øst-Norge and the Norwegian Social Science Data Services approved the study.

\section{Injury definition}

The injury definition was "All injuries that occurred during training or competition and required attention by medical personnel." This definition, as well as the classification of the type of injury and body part injured, was based on a recent consensus document on injury surveillance in football. ${ }^{11}$ Training included activities on snow, and basic training not on snow. We classified the severity of injury according to the duration of absence from training and competition as slight (no absence); minimal (1 to 3 days), mild ( 4 to 7 days), moderate ( 8 to 28 days) and severe ( $>28$ days) as also recommended in the consensus report. ${ }^{11}$ For each injury, we recorded the body part injured, the injury type, as well as the specific diagnosis. If multiple injuries resulted from the same event, we described all of these on the same form. We also recorded information on where the injury happened, during World Cup/World Ski Championship competition/official training, other competition/official training, other training activity on snow (ie, regular training) or basic training not on snow (ie, running, weightlifting, soccer, etc). For injuries recorded during the interviews, the interviewer completed an injury form containing the abovementioned information. ${ }^{10}$

\section{Statistics including injury incidence and exposure}

To present the most complete picture of injury risk, we have expressed injury incidence as the absolute injury rate (expressed as the total number of injuries per 100 athletes per season) as well as the relative injury rate (expressed corrected for exposure as the number of injuries per 1000 runs), both with their corresponding $95 \%$ CIs. When calculating the absolute injury rate we included all injuries during the season, in competition as well as during training. To calculate the relative injury rate, we included injuries in World Cup/World Ski Championship competitions, as these were the only competitions where it was possible to relate injuries to the number of started runs (exposure) across the different disciplines. For each of the skiers, we calculated their competition exposure as the exact number of started runs during the 2006-7 and 2007-8 winter seasons based on information from the FIS database. The database includes information on race completion, and we included the run if the athlete was disqualified afterwards but counted only one run if the athlete was disqualified after the first run in slalom and giant slalom (where there are two runs per event).

We based our calculation on the Poisson model and used a Z test for comparing injury risk between disciplines and computing the corresponding $95 \% \mathrm{CI}$. We computed relative risks (RR) with their $95 \%$ CIs to compare injury rates between male and female athletes for severity, distribution with regard to body part injured and the relative risk between the different disciplines for all injuries and knee injuries. A two-tailed p level of $\leqslant 0.05$ was considered statistically significant.

\section{RESULTS}

In total, 521 alpine athletes (292 males and 229 females) were interviewed during the 2006-7 and the 2007-8 winter seasons from the selected nations. Of these, 207 interviews (40\%) were done with the athletes and 314 (60\%) with coaches/medical personnel. Five athletes were interviewed via the telephone/ email within 4 weeks after the interviews. This represents a $100 \%$ response rate for athletes on the World Cup teams selected for the study.

A total of 191 acute injuries (123 among males and 68 among females) were recorded. The absolute injury rate, expressed as the number of injuries per 100 athletes per season, is shown for all injuries within the different severity categories for males and females in table 1 . There was a higher risk for males compared with females for all injuries, while no significant gender difference was detected for time-loss injuries only.

As many as 155 (81.1\%) of the injuries recorded were timeloss injuries; the majority of these were moderate and severe injuries. Overall, 111 (58.1\%) were located in the lower extremity. The most commonly injured body part was the knee ( $n=68,35.6 \%$ ), and $37(54.4 \%)$ of these were severe with an absence of $>28$ days (table 2 ). The second most frequently injured body parts were the lower leg, where $31.8 \%$ were severe injuries, and the lower back region, where only $4.5 \%$ were severe (table 2). The injury distribution is shown separately for males and females in fig 1 . There was no difference in the absolute rate

Table 1 Absolute injury rates with $95 \%$ Cls for all recorded injuries $(n=191)$ among males and females related to injury severity

\begin{tabular}{llllll}
\hline \multirow{2}{*}{ Absence } & \multicolumn{2}{l}{ Incidence (injuries/100 athletes per season) } & & Relative risk \\
\cline { 2 - 3 } \cline { 5 - 6 } & Male & Female & Total & Males versus females \\
\hline None & $9.2(5.8$ to 12.7$)$ & $3.9(1.4$ to 6.5$)$ & $6.9(4.7$ to 9.2$)$ & & $2.35(1.11$ to 5.00$)$ \\
1-3 days & $3.4(1.3$ to 5.5$)$ & $2.6(0.5$ to 4.7$)$ & $3.1(1.6$ to 4.6$)$ & & $1.31(0.48$ to 3.60$)$ \\
4-7 days & $6.5(3.6$ to 9.4$)$ & $4.4(1.7$ to 7.1$)$ & $5.6(3.5$ to 7.6$)$ & & $1.49(0.69$ to 3.21$)$ \\
8-28 days & $11.3(7.4$ to 15.2$)$ & $7.9(4.2$ to 11.5$)$ & $9.8(7.1$ to 12.5$)$ & & $1.44(0.81$ to 2.55$)$ \\
$>$ 28 days & $11.6(7.7$ to 15.6$)$ & $10.9(6.6$ to 15.2$)$ & $11.3(8.4$ to 14.2$)$ & & $1.07(0.64$ to 1.79$)$ \\
Total & $42.1(34.7$ to 49.6$)$ & $29.7(22.6$ to 36.8$)$ & $36.7(31.5$ to 41.9$)$ & & $1.42(1.06$ to 1.91$)$ \\
\hline
\end{tabular}

Relative risk with $95 \%$ Cls between males and females is shown for each severity category. 
Table 2 Distribution of all recorded injuries $(n=191)$ with respect to body part injured and severity category (classified according to the number of days of absence from training and competition)

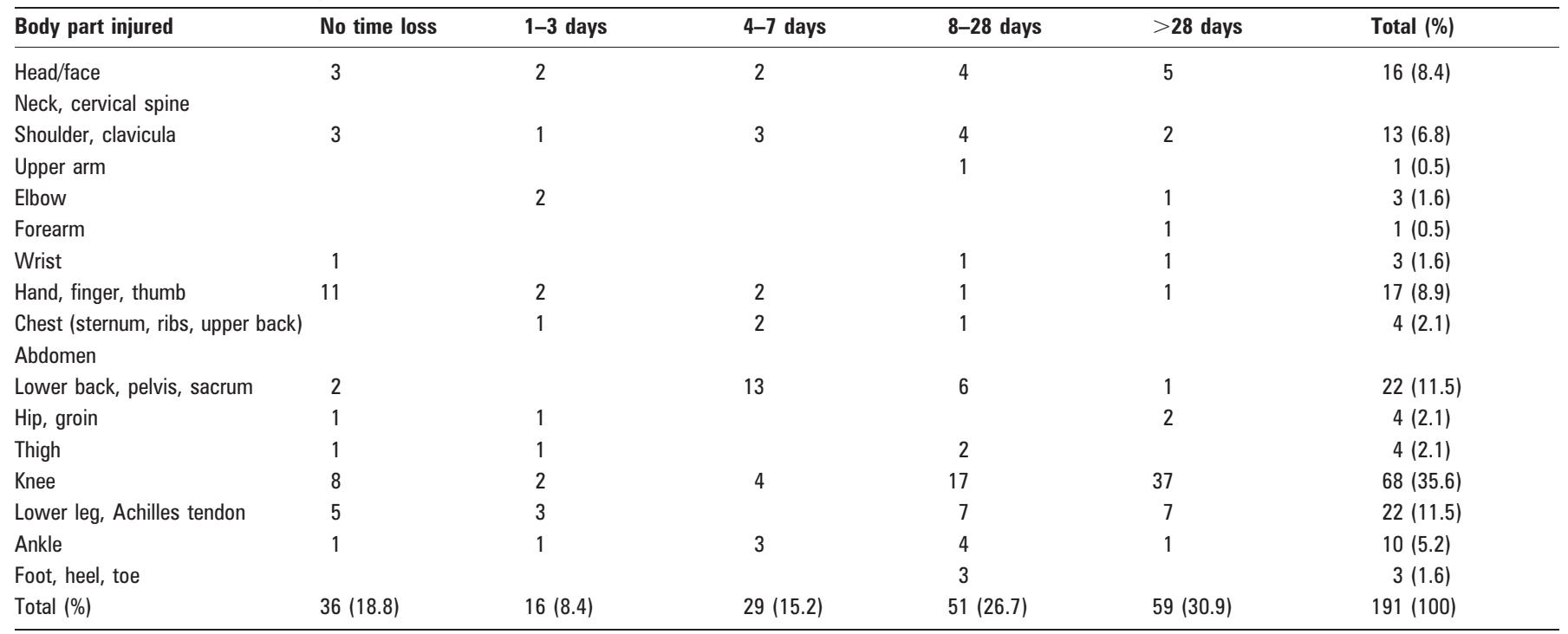

for knee injuries between males and females (RR 1.06, 95\% CI 0.65 to 1.71$)$.

The most common injury type in alpine skiing was joint and ligament injuries (44.0\%) followed by fractures and bone stress $(18.8 \%)$ (table 3$)$. For both injury types, the majority were severe injuries (42.9\% for joint and ligament injuries and $41.7 \%$ for fractures and bone stress). As shown in table 4, the knee accounted for 57 (67.9\%) of all joint and ligament injuries, and knee ligament injuries were the most frequent injury type

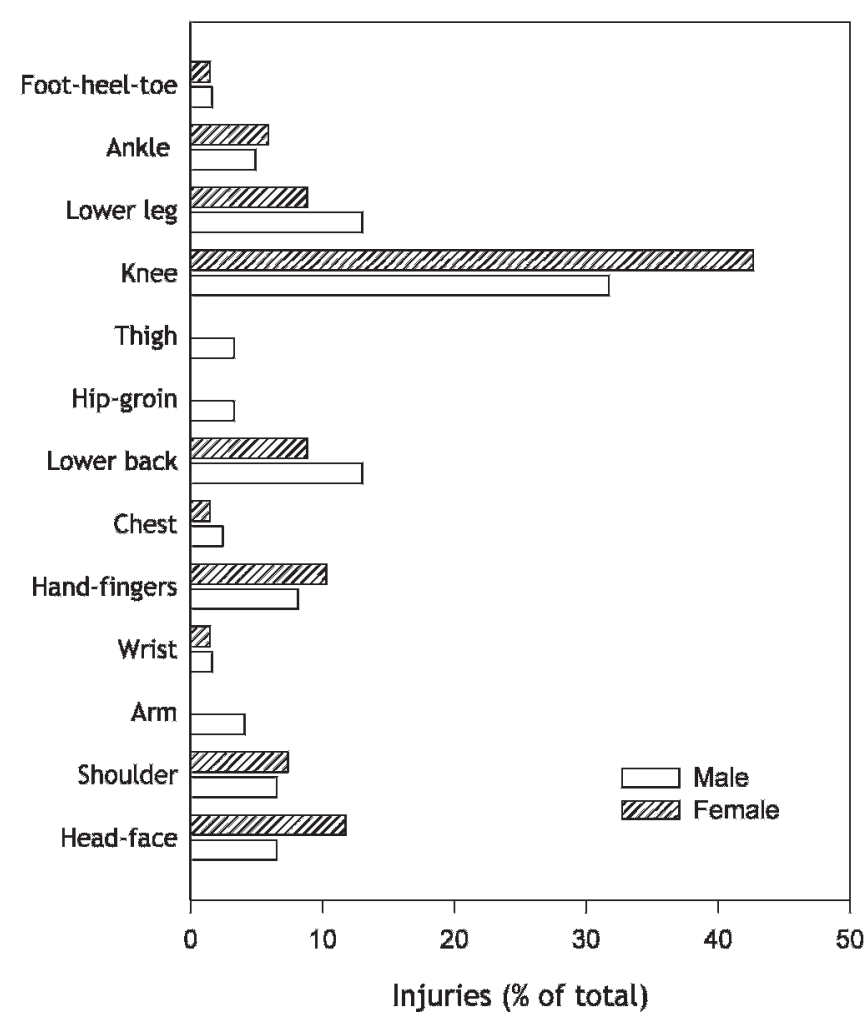

Figure 1 Distribution by body region of all reported injuries $(n=191)$ expressed as the percentage of the total number reported for males ( $n=123$; open bars) and females ( $n=68$; hatched bars). (table 4). Of these, ACL injuries was the most frequent specific diagnosis $(n=26)$. We found no difference between males and females in the risk for ACL injuries (RR 1.08, 95\% CI 0.50 to 2.36). Concussions followed as the second most common specific injury type $(n=11)$.

Of the 191 injuries, 86 (45.0\%) occurred during World Cup/ World Ski Championship competitions, 31 (16.2\%) during official training for these competitions, while 48 (25.1\%) injuries occurred during regular training on snow. Of the remaining injuries, $24(12.6 \%)$ occurred during other competitions/official training and $2(1.0 \%)$ during basic training not on snow. Based on the FIS database, we estimated the total exposure during World Cup/World Ski Championship competitions for the athletes interviewed to be 8734 runs (table 5). The relative injury rate, estimated as the number of injuries per 1000 runs, was 9.8 (95\% CI 7.8 to 11.9). Of the 86 injuries, 67 led to time loss from training/competition, corresponding to a relative rate of 7.7 injuries per 1000 runs for time-loss injuries. The relative injury rate across the different disciplines for all injuries $(n=86)$ as well as knee injuries $(n=28)$ is shown for males and females in table 5. For all injuries, the highest incidence was found for downhill followed by super-G and giant slalom, while the incidence was lowest in slalom. There was a significant difference between downhill (RR 3.48, 95\% CI 1.93 to 6.25) and super-G (RR 2.23, 95\% CI 1.09 to 4.56) compared with slalom, as well as for downhill compared with giant slalom (RR $1.87,95 \%$ CI 1.07 to 3.25$)$. Slalom was the only discipline where there was a difference in relative injury rate between males and females (RR 5.16, 95\% CI 1.17 to 22.7). However, there was no difference in the relative rate for knee injury between males and females in any discipline.

\section{DISCUSSION}

This is the first large cohort study to examine the overall injury risk and detailed injury pattern among World Cup alpine skiers during the competitive season. The main findings were that the injury rate for elite alpine skiers was higher than reported previously, that the injury rate increased with skiing speed and that the absolute and relative injury rate was higher among males compared with females. The knee was the most commonly injured body part, with a majority of severe injuries. 
Table 3 Distribution of all recorded injuries with respect to injury type and severity category (classified according to the number of days of absence from training and competition)

\begin{tabular}{|c|c|c|c|c|c|c|}
\hline & No time loss & 1-3 days & 4-7 days & 8-28 days & $>28$ days & Total $(\%)$ \\
\hline \multicolumn{7}{|l|}{ Injury type } \\
\hline Fractures/bone stress & 9 & 2 & 3 & 7 & 15 & $36(18.8)$ \\
\hline Joint/ligament & 11 & 5 & 8 & 24 & 36 & $84(44.0)$ \\
\hline Muscle/tendon & 3 & 3 & 8 & 6 & & $20(10.5)$ \\
\hline Contusion & 8 & 4 & 5 & 6 & & $23(12.0)$ \\
\hline Skin/laceration & 2 & & 1 & 2 & 2 & $7(3.7)$ \\
\hline Nervous system/concussion & 1 & 2 & 4 & 3 & 5 & $15(7.9)$ \\
\hline Other & 2 & & & 3 & 1 & $6(3.1)$ \\
\hline Total & 36 & 16 & 29 & 51 & 59 & $191(100)$ \\
\hline
\end{tabular}

To describe overall injury risk and enable a comparison with other studies and sports, we have estimated both the absolute rate (per season) and relative rate (per run). Through the FIS database, we could extract a complete record of the exact numbers of runs during World Cup/World Ski Championship competitions for each of the athletes interviewed. Therefore, the relative rate of 9.8 injuries per 1000 runs $(7.7$ injuries per 1000 runs for time-loss injuries) represents a reliable estimate. There are only two previous studies available on World Cup alpine skiers, which reported an incidence of 1.9 and 4.0 injuries per 1000 runs, respectively. ${ }^{4}$ However, these studies were based on data from just one major event with few injuries recorded, and the injury definition, with regard to severity, was not clearly defined. Our findings indicate that the injury risk in WC/ WSC competition is at least twice as high as previously suggested. One limitation of our approach is that exact exposure data were only available for World Cup/World Ski Championship competitions, not training outside these competitions. Obtaining documentation on the number of runs performed or the time spent in active training is challenging, and much of the technical training cannot be attributed to one specific discipline.

When comparing the injury risk between disciplines, it should also be borne in mind that the length of a run varies between disciplines. Downhill consists of only one run and has the longest course (ranging from around 2000 to $4500 \mathrm{~m}$ ), the largest vertical drop (800 to $1100 \mathrm{~m}$ for males, 450 to $800 \mathrm{~m}$ for females) and hence the highest speed (average 95 to $105 \mathrm{~km} / \mathrm{h}$, maximal speed can exceed $140 \mathrm{~km} / \mathrm{h}$ ). ${ }^{12}$ At the other end of the spectrum is slalom, with two runs, the shortest course, the lowest vertical drop (180 to $220 \mathrm{~m}$ for men, 140 to $220 \mathrm{~m}$ for women), and frequent turns (on average 60 gates) designed to combine speed with neat execution and precision of turns. ${ }^{12}$ Another difference is that ski and safety equipment varies between disciplines, although crash helmets are compulsory in all competitions. One study from the 1980s showed that twothirds of the injuries were reported to have occurred downhill, ${ }^{7}$ and two more recent single-event studies have an incidence of 1.1 and 8.3 injuries per 1000 runs, respectively. ${ }^{45}$ Our results confirm that downhill is associated with the highest injury risk but also document that the incidence, 17.2 injuries per 1000 runs, is much higher than previously reported. We also found that the risk of injury increased with increasing speed, from the lowest in slalom to the highest in downhill. Notably, among World Cup alpine skiers the injury rate increases with severity; as many as $38 \%$ of all time-loss injuries cause an absence of $>$ 28 days. This is in contrast to most other sports, where severe injuries are the least frequent. If we consider the challenges involved-manoeuvring down an icy, steep mountainside on a pair of skies with minimal protection, often above the speed limit-these findings are not surprising. However, whether there has been an increase in severe injuries or in downhill

Table 4 Distribution of all recorded injuries $(n=191)$ with respect to body part injured and injury type

\begin{tabular}{|c|c|c|c|c|c|c|c|c|}
\hline Body part & $\begin{array}{l}\text { Fractures and } \\
\text { bone stress }\end{array}$ & $\begin{array}{l}\text { Joint and } \\
\text { ligament }\end{array}$ & $\begin{array}{l}\text { Muscle and } \\
\text { tendon }\end{array}$ & Contusions & $\begin{array}{l}\text { Lacerations and } \\
\text { skin lesions }\end{array}$ & $\begin{array}{l}\text { Nervous system/ } \\
\text { concussion }\end{array}$ & Other & Total $(\%)$ \\
\hline Head, face & 2 & & & 1 & 2 & 11 & & $16(8.4)$ \\
\hline \multicolumn{9}{|l|}{ Neck, cervical spine } \\
\hline Upper arm & 1 & & & & & & & $1(0.5)$ \\
\hline Elbow & & 3 & & & & & & $3(1.6)$ \\
\hline Forearm & 1 & & & & & & & $1(0.5)$ \\
\hline $\begin{array}{l}\text { Chest (sternum, ribs, } \\
\text { upper back) }\end{array}$ & 1 & & & 3 & & & & $4(2.1)$ \\
\hline \multicolumn{9}{|l|}{ Abdomen } \\
\hline $\begin{array}{l}\text { Lower back, pelvis, } \\
\text { sacrum }\end{array}$ & 1 & 2 & 7 & 6 & 1 & 4 & 1 & $22(11.5)$ \\
\hline Hip, groin & & & 2 & & 1 & & 1 & $4(2.1)$ \\
\hline Foot, heel, toe & 1 & & & & & & 2 & $3(1.6)$ \\
\hline Total & 36 & 84 & 20 & 23 & 7 & 15 & 6 & $191(100)$ \\
\hline
\end{tabular}




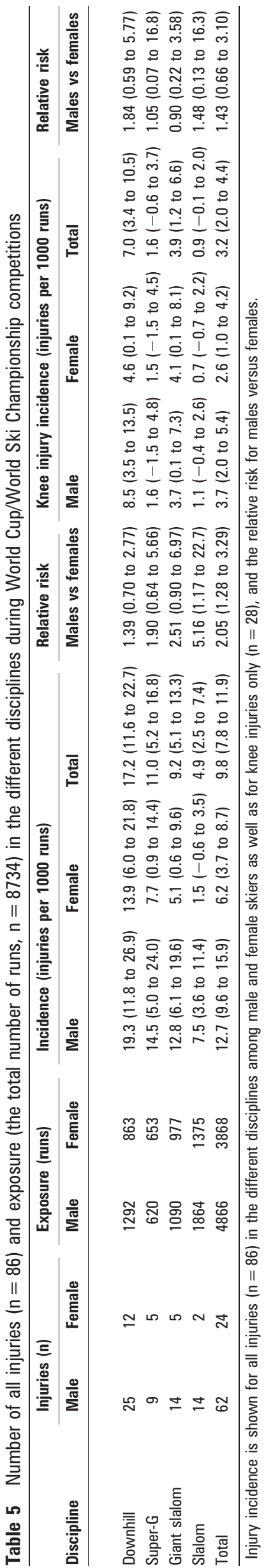

because of the development of the sport and its equipment, or the actual risk has been higher than previously reported, is difficult to know. Continuous injury surveillance is needed to follow such trends.

While several studies have shown that the knee is the most commonly injured body part among adult recreational skiers, ${ }^{13-16}$ there is less evidence on elite alpine skiers. One study among top-ranked skiers from the 1980s found knee ligament injury to be the most frequent injury type, while a lateral ligament ankle sprain was the most frequent specific diagnosis. ${ }^{7}$ We also found the knee to be the most commonly injured body part among World Cup skiers, accounting for $36 \%$ of all injuries, while ankle sprains were rare. ACL injury was the most commonly reported specific diagnosis, accounting for 38\% of knee injuries. Moreover, we have most likely underestimated the number of ACL injuries, as the person interviewed in several cases could not give a precise diagnosis. However, about half of the knee injuries were severe, causing $>28$ days of time loss from sports. Our findings are supported by a recent study by Pujol and coworkers, ${ }^{17}$ who observed a high frequency of ACL injuries among top-ranked French alpine skiers during a 25-year period. Preventing severe knee injuries should therefore be a priority.

Several mechanisms have been described to cause ACL injuries in alpine skiing, ${ }^{18-24}$ but as most of this research has been done on recreational skiers, we do not know if these are relevant for alpine skiers at the World Cup level. The bootinduced anterior drawer mechanism, which occurs during hard landings in deep knee flexion after a jump, has been described to be more common among high-level skiers. ${ }^{24}$ Our data show that the incidence of knee injuries was highest in downhill and lowest in slalom. This suggests that not only can the high technical demands and forces involved in the technical disciplines (giant slalom and slalom) cause the ACL to tear, but also the high-speed disciplines may be even more risky. However, at present we do not even know if the injuries are caused by loads occurring while the athlete is still skiing, or if the ACL is torn in crashes where the athlete tumbles down the slope, with the heavy ski acting as a lever. Before preventive measures can be suggested, the injury mechanisms need to be characterised.

Our data suggest that the injury risk is higher for male than female elite skiers. The injury incidence in World Cup/World Ski Championship competitions was twice as high in males. The overall injury risk during the winter season was also higher in male skiers. Our results are in contrast with data from the 1994 Olympic Games ${ }^{4}$ and the 1995 World Junior Championships, ${ }^{5}$ where females had a significantly higher injury incidence than males. No sex differences were, however, reported among national competitive skiers during the 1981/2 season. ${ }^{25}$ The present study is the first to report a higher injury incidence among males, although it should be noted that we found no significant differences when only time-loss injuries were included.

For knee injury risk, however, we detected no sex differences. Our findings are in line with Pujol and coworkers, ${ }^{17}$ who found no sex differences in ACL injury risk among elite French national team athletes during 25 years. Ekeland and coworkers, ${ }^{4}$ on the other hand, reported a significantly higher percentage of previous ACL injuries in Olympic female alpine racers, but this was a study of 54 competitors ${ }^{4}$ with a response rate of only $21 \%$. Several studies among recreational skiers have reported a twofold greater risk of knee injuries among women compared with men. ${ }^{13}{ }^{26-28}$ In team sports like soccer and team handball, women have a four- to sixfold higher rate of non-contact ACL 


\section{What is already known on this topic}

- There are no data from large cohort studies on the injury risk and pattern among elite alpine skiers.

- There are conflicting study findings regarding sex differences in injury risk among competitive alpine skiers.

\section{What this study adds}

- The injury rate among World Cup alpine skiers during the competitive season is high, particularly for severe knee injuries.

- Injury rate across disciplines increases with increasing speed.

- Males have an increased risk compared with females.

injuries than men. ${ }^{29-32}$ Perhaps the speed, technical demands and high forces associated with World Cup skiing over-rule any vulnerability factors related to sex.

Some limitations must be kept in mind when interpreting the results from this study. Recall bias is a challenge with retrospective interviews. However, we did find this to be the best method available to record injuries among skiers and snowboarders. ${ }^{10}$ If not all injuries were captured through the interviews, the injury rate in alpine skiing will have been underestimated. However, this is the most comprehensive survey conducted among World Cup skiing athletes to date. Another limitation is that we have recorded injuries only through the World Cup winter season, and we do not know what occurs in the training season. Although the athletes do much of their training on snow all year round, some changes in the overall pattern and injury risk would be likely if we had been able to include the entire year.

Acknowledgements: We would like to thank the alpine World Cup athletes, coaches and medical team personnel who participated in this study and the International Ski Federation staff and officials for all practical support.

Funding: This project has been established through a generous grant from djo and the International Ski Federation (FIS). The Oslo Sports Trauma Research Center has been established at the Norwegian School of Sport Sciences through grants from the Royal Norwegian Ministry of Culture and Church Affairs, the South-Eastern Norway Regional Health Authority, the Norwegian Olympic Committee \& Confederation of Sport and Norsk Tipping AS.

Competing interests: None.

Ethics approval: Ethics approval was provided by Regional Committee for Medical Research Ethics, Region Øst-Norge and the Norwegian Social Science Data Services.

Patient consent: Obtained.

Provenance and peer review: Commissioned; not externally peer reviewed.

\section{REFERENCES}

1. Ekeland A, Rødven A. Injury trends in Norwegian ski resorts in the 10 year period 1996-2006. J ASTM Int 2009:5:31-8.

2. Johnson RJ, Ettlinger CF, Shealy JE. Update on injury trends in alpine skiing. J ASTM Int 2009:5:11-22.

3. Laporte J-D, Binet M-H, Constans D. Evolution of ACL Ruptures in French Ski Resorts 1992-1999. In: Johnson RJ, Zucco P, Shealy JE, eds. Skiing trauma and safety: thirteenth volume, ASTM STP 1397. West Conshohocken: American Society for Testing and Materials, 2000:95-107.

4. Ekeland A, Dimmen S, Lystad $\mathrm{H}$, et al. Completion rates and injuries in alpine races during the 1994 Olympic Winter Games. Scand J Med Sci Sports 1996;6:287-90.

5. Bergstrøm KA, Bergstrøm A, Ekeland A. Organisation of safety measures in an alpine World Junior Championship. Br J Sports Med 2001;35:321-4.

6. Margreiter R, Raas E, Lugger LJ. The risk of injury in experienced alpine skiers. Orthop Clin North Am 1976;7:51-4.

7. Raas E. Some aspects of injuries in competitive skiers. In: Hauser W, Karlsson J, Magi M, eds. Ski trauma and skiing safety IV. TUEV edn, Munich, 1982:202-6.

8. Ekeland A. The knees are in danger in skiing. Scand J Med Sci Sports 1995;5:61-3.

9. Ekeland A, Nordsletten L, Lystad $\mathrm{H}$, et al. Previous skiing injuries in alpine Olympic racers. In: Johnson RJ, Mote Jr CD, Ekeland A, eds. Skiing trauma and safety: eleventh volume, ASTM STP 1289. Philadelphia: American Society for Testing and Materials, 1997:7-13.

10. Flørenes TW, Nordsletten L, Heir S, et al. Recording injuries among World Cup skiers and snowboarders: a methodological study. Scand J Med Sci Sports. In press.

11. Fuller CW, Ekstrand J, Junge A, et al. Consensus statement on injury definitions and data collection procedures in studies of football (soccer) injuries. Br J Sports Med 2006;40:193-201.

12. FIS. FIS International Ski Competition Rules ICR 2008. http://www.fis-ski.com/data/ document/icr2008.pdf (accessed August 2009)

13. Davidson TM, Laliotis AT. Alpine skiing injuries. A nine-year study. West J Med 1996;164:310-14.

14. Sutherland AG, Holmes JD, Myers S. Differing injury patterns in snowboarding and alpine skiing. Injury 1996;27:423-5.

15. Langran M, Selvaraj S. Snow sports injuries in Scotland: a case-control study. Br J Sports Med 2002;36:135-40.

16. Ekeland A, Rødven A. Injuries in Norwegian ski resorts the winter seasons of 2005 and 2006. J ASTM Int 2009:5:43-8.

17. Pujol N, Blanchi MP, Chambat $P$. The incidence of anterior cruciate ligament injuries among competitive alpine skiers: a 25-year investigation. Am J Sports Med 2007:35:1070-4.

18. Johnson RJ. Prevention of cruciate ligament injuries. In: Feagin Jr JA, ed. The crucial ligaments. New York: Churchill Livingstone, 1988:349-56.

19. Johnson RJ, Renstrom PAFH. Injuries in alpine skiing. In: Renstrom PAFH, ed. Clinical practice of sports injury prevention and care. Oxford: Blackwell Scientific, 1994:676-98.

20. Ettlinger CF, Johnson RJ, Shealy JE. A method to help reduce the risk of serious knee sprains incurred in alpine skiing. Am J Sports Med 1995;23:531-7.

21. Johnson SC. Anterior cruciate ligament injury in elite alpine competitors. Med Sci Sports Exerc 1995;27:323-7.

22. Natri A, Beynnon BD, Ettlinger CF, et al. Alpine ski bindings and injuries. Current findings. Sports Med 1999;28:35-48.

23. Jarvinen $\mathbf{M}$, Natri A, Laurila $\mathrm{S}$, et al. Mechanisms of anterior cruciate ligament ruptures in skiing. Knee Surg Sports Traumatol Arthrosc 1994;2:224-8.

24. McConkey JP. Anterior cruciate ligament rupture in skiing. A new mechanism of injury. Am J Sports Med 1986;14:160-4.

25. Ekeland A, Holm A. Injury and race completion rates in alpine competitions. In: Johnson RJ, Mote Jr CD, eds. Skiing trauma and safety: fifth international symposium, ASTM STP 860. Philadelphia: American Society for Testing and Materials, 1985:293-301.

26. Shealy JE, Ettlinger CF. Gender-related injury patterns in skiing. In: Mote Jr CD, Johnson RJ, Hauser W, et al, eds. Skiing trauma and safety: tenth volume, ASTM STP 1266. Philadelphia: American Society for Testing and Materials, 1996:45-57.

27. Greenwald RM, Toelcke T. Gender differences in alpine skiing injuries: a profile of the knee-injured skier. In: Johnson RJ, Mote Jr CD, Ekeland A, eds. Skiing trauma and safety: eleventh international symposium, ASTM STP 1289. West Conshohocken: American Society for Testing and Materials, 1997:111-21.

28. Ekeland A, Sulheim S, Rødven A. Injury rates and injury types in alpine skiing, telemarking, and snowboarding. In: Johnson RJ, Shealy JE, Ahlbäumer MG, eds. Skiing trauma and safety: fifteenth volume, ASTM STP 1464. West Conshohocken: American Society for Testing and Materials, 2005:31-9.

29. Arendt E, Dick R. Knee injury patterns among men and women in collegiate basketball and soccer. NCAA data and review of literature. Am J Sports Med 1995;23:694-701.

30. Bjordal JM, Arnly F, Hannestad B, et al. Epidemiology of anterior cruciate ligament injuries in soccer. Am J Sports Med 1997;25:341-5.

31. Myklebust G, Maehlum S, Holm I, et al. A prospective cohort study of anterior cruciate ligament injuries in elite Norwegian team handball. Scand J Med Sci Sports 1998;8:149-53.

32. Agel J, Arendt EA, Bershadsky B. Anterior cruciate ligament injury in national collegiate athletic association basketball and soccer: a 13-year review. Am J Sports Med 2005:33:524-30. 